\title{
A regulação das relações de trabalho \\ e o gerenciamento de recursos humanos em enfermagem
}

\section{LA REGULACIÓN DE LAS RELACIONES DE TRABAJO Y LA GERENCIA DE LOS RECURSOS HUMANOS EN ENFERMERÍA}

Genival Fernandes de Freitas', Fernanda Maria Togeiro Fugulin², Maria de Fátima Prado Fernandes ${ }^{3}$

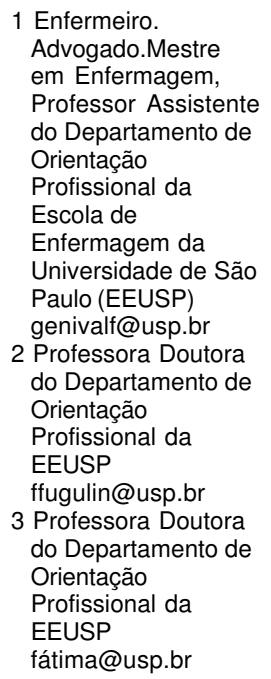

\begin{abstract}
RESUMO
Este artigo tem a finalidade de discorrer sobre a regulação das relações de trabalho na enfermagem, subsidiando a prática gerencial do enfermeiro, no que se refere aos direitos e obrigações de empregados e empregadores, baseandose na Consolidação das Leis Trabalhistas (CLT) e das normas constitucionais. Enfatiza algumas normatizações que suscitam dúvidas e conflitos no cotidiano profissional do enfermeiro, tais como: duração da jornada de trabalho, períodos de descanso intra e entre jornadas, horas extraordinárias, descanso semanal remunerado e alterações de turnos de trabalho, considerando que a conformação do exercício profissional com o processo legal amplia as possibilidades do enfermeiro atuar junto à equipe com mais propriedade e segurança, respeitando os direitos dos profissionais e dos clientes, reduzindo,

ABSTRACT

This paper is aimed at discoursing on the regulation of labor relations in Nursing and at giving subsidies to the nurse's managerial practice concerning the rights and obligations of employees and employers based on the Brazilian Labor Law and the Federal Constitution. It emphasizes some regulations that are not clear enough and give rise to doubts and conflicts on the nurse's daily professional activities, such as working hours, resting periods in and between journeys, extra pay for overtime work, weekly paid rest and changes in work schedule. The adequacy of nursing practice to legal rules should allow nurses to get more knowledge, resulting in more confidence and safer actions. By having professional and patient's rights respected, occasional juridical problems inherent to labor rights and obligations will be reduced.
\end{abstract} ainda, eventuais problemas jurídicos inerentes aos direitos e deveres trabalhistas.

\section{DESCRITORES}

Legislação de enfermagem.

Recursos humanos de

enfermagem.

Pesquisa em administração de enfermagem.

\section{KEY WORDS}

Legislation, nursing.

Nursing staff.

Nursing administration research.

\section{RESUMEN}

Este artículo tiene la finalidad de discurrir sobre la regulación de las relaciones de trabajo en enfermería, subsidiando la práctica gerencial del enfermero, en lo que se refiere a los derechos y obligaciones de empleados y empleadores, basándose en la Consolidación de las Leyes Trabajadoras (CLT) y de las normas constitucionales. Enfatiza algunas normatizaciones que suscitan dudas y conflictos en el cotidiano profesional del enfermero, tales como: duración de la jornada de trabajo, períodos de descanso intra y entre jornadas, horas extraordinarias, descanso semanal remunerado y alteraciones de turnos de trabajo, considerando que la conformación del ejercicio profesional con el proceso legal amplía las posibilidades del enfermero para actuar junto al equipo con más propiedad y seguridad, respetando los derechos de los profesionales y de los clientes, reduciendo, aún, eventuales problemas jurídicos inherentes a los derechos y deberes del trabajador.

\section{DESCRIPTORES}

Legislación de enfermería. Personal de enfermería. Investigación en administración de enfermería. 


\section{INTRODUÇÃO}

As dúvidas dos administradores e gerentes de serviços de saúde acerca das legislações e normatizações trabalhistas têm causado alguns problemas no cotidiano do gerenciamento de recursos humanos das instituições, fazendo com que esses profissionais, muito freqüentemente, tomem decisões equivocadas em relação à regulação do trabalho de seus funcionários, por desconhecerem aspectos legais que envolvem os direitos e deveres de empregados e empregadores.

Estas legislações foram historicamente estabelecidas, de acordo com o contexto social, político e econômico, respondendo à evolução dos modos de produção e à necessidade de regulação econômica e social do trabalho.

O fortalecimento do modo de produção capitalista, a partir da Revolução Industrial (segunda metade do século XVIII, na Europa), marca um período de superexploração da força de trabalho assalariada.

Nesse contexto, a história do trabalho humano revela que as lutas dos operários, ao longo dos séculos, culminaram com o estabelecimento de movimentos de associação entre os trabalhadores (século XIX), como forma de defesa contra as ações abusivas dos empregadores, e com a intervenção do Estado nas relações trabalhistas (início do século XX), por meio da promulgação de normas estatais reguladoras dos direitos e deveres de trabalhadores e patrões.

Dessa forma, a autonomia dos empregadores foi limitada e alguns direitos dos trabalhadores reconhecidos, destacando-se, entre esses, a limitação da jornada de trabalho, a regulamentação da concessão de períodos de repouso, o estabelecimento de valor para o salário mínimo e de mecanismos de proteção do trabalhador contra a demissão arbitrária.

No Brasil, somente a partir de 1930 foram editadas as primeiras leis referentes às questões trabalhistas. Em $1^{\circ} \mathrm{de}$ maio de 1943 entrou em vigor a Consolidação das Leis Trabalhistas $(\mathrm{CLT})^{(1)}$, por meio do Decreto-Lei n ${ }^{\circ} 5542$, que regulam as relações trabalhistas até os dias de hoje. Para preencher as lacunas da CLT, a Constituição Federal ${ }^{(2)}$ de 1988, as convenções sindicais e outras legislações suplementares foram e vêm sendo editadas.

No entanto, o contexto político e econômico atual tem, cada vez mais, interferido na organização e na regulação das relações de trabalho e, consequentemente, nas políticas de recursos humanos das organizações, fazendo com que seus gestores, na tentativa de equacionar seus problemas finan- ceiros, optem pela redução do quantitativo de recursos humanos ou pela adoção de medidas de flexibilização das relações de trabalho, incluindo a terceirização dos serviços, que repercutem, diretamente, na estruturação da dinâmica social do trabalho e do trabalhador, na qualidade dos serviços prestados e na legitimidade dos interesses trabalhistas.

O trabalho dos profissionais de saúde também é regido por essas legislações e sofre influências do contexto social, político e econômico.

A enfermagem, praticada por profissionais com diferentes tipos de formação (enfermeiros, técnicos e auxiliares de enfermagem), coordenados pelo enfermeiro, caracteriza-se pelo desenvolvimento de processos de trabalho singulares e pela necessidade de assistência contínua ao paciente, que exige a realização de turnos ininterruptos de revezamento, plantões de final de semana, noturnos e feriados.

O trabalho do enfermeiro envolve, ainda, atribuições gerenciais que exigem conhecimentos e competências que o habilitam para participar dos processos decisórios e para assumir papel relevante no direcionamento das políticas de recursos humanos dentro das instituições de saúde.

Assim, considerando que no desenvolvimento de suas atribuições gerenciais e durante os processos de tomadas de decisões administrativas, os enfermeiros devem observar os direitos e deveres dos seus subordinados, o presente artigo tem o objetivo de discorrer sobre aspectos da legislação trabalhista interve-nientes na prática e no cotidiano da equipe de enfermagem, subsidiando o exercício gerencial desses profissionais, contribuindo, também, para o fortalecimento das relações de trabalho entre os integrantes da equipe.

Nessa perspectiva, abordaremos alguns direitos e deveres dos profissionais de enfermagem relacionados aos principais aspectos trabalhistas que suscitam dúvidas e conflitos na prática gerencial do enfermeiro.

\section{JORNADA DE TRABALHO}

Jornada de trabalho é o tempo em que o empregado permanece à disposição do empregador ${ }^{(3)}$. Três autores ${ }^{(3-5)}$ mencionam que a CLT estabelece uma jornada máxima de oito horas diárias e de quarenta e quatro horas semanais de trabalho.

Na enfermagem, a carga horária semanal de trabalho varia de trinta a quarenta horas semanais, sendo mais comum a jornada de trinta e seis horas/semana. As jornadas diárias de trabalho variam de seis, oito e doze por trinta e seis horas, 
ou ainda, jornadas de quatro dias de seis horas e um dia de doze horas, conforme o contrato de trabalho ${ }^{(3)}$.

De acordo com o art. . $^{\circ}$ da Constituição Federal ${ }^{(2)}(\mathrm{CF}) / 88$,

São direitos dos trabalhadores[...] jornada de seis horas para o trabalho realizado em turnos ininterruptos de revezamento, salvo negociação coletiva.

A negociação coletiva envolve acordo ou convenção. $\mathrm{O}$ acordo coletivo é o instrumento firmado entre uma ou mais empresas e uma categoria profissional, enquanto a convenção coletiva é firmada por duas entidades sindicais ${ }^{(3)}$.

Mediante esse entendimento, consideramos que nas instituições de saúde onde se desenvolvem atividades ininterruptas, as jornadas de oito e doze horas, praticadas pelos profissionais de enfermagem, encontram-se resguardadas nas convenções coletivas de trabalho.

A redução de jornada é possível mediante acordo ou convenção coletiva de trabalho. Porém, a jornada normal não poderá ser reduzida pelo empregador com diminuição do salário, mesmo com a concordância do empregado, salvo se houver efetivo interesse deste, por motivos como freqüência a aulas ou cursos e outro emprego ${ }^{(5)}$.

\section{Períodos de descanso intra e entre jornadas}

Alguns períodos de descanso são obrigatórios durante a jornada de trabalho para todos os trabalhadores, incluindo os profissionais de enfermagem. Haverá descanso obrigatório de quinze minutos, quando a jornada de trabalho ultrapassar quatro horas, não excedendo o limite de seis horas diárias (art. 71, parágrafo $1 .^{\circ}$ da CLT) ${ }^{(1)}$. A concessão desse descanso não será computada na jornada de trabalho(3).

No exercício profissional de enfermagem, devido a natureza das atividades, é comum que os trabalhadores, principalmente os enfermeiros, deixem de usufruir deste seu horário de descanso, devido a demanda de ações que não podem deixar de ser realizadas, adiadas ou interrompidas, como por exemplo a participação em atendimentos caracterizados como urgência ou emergência.

Se a jornada diária ultrapassar seis e não exceder oito horas, o intervalo de descanso deverá ser de no mínimo uma hora e no máximo duas, não computadas na jornada diária de trabalho ${ }^{(3)}$. Exemplo: o profissional de enfermagem que cumpre jornada de trabalho de oito horas diárias, iniciando suas atividades às sete horas, quando realiza um intervalo de uma hora para refeição/ descanso, terá cumprido sua jornada de trabalho às dezesseis horas e não às quinze horas, uma vez que o período de descanso não é contado como parte de sua jornada diária de trabalho.

Caso o funcionário trabalhe em jornada que exceda seis horas e não lhe seja concedido pelo empregador esse direito de descanso intra jornada, o mesmo ficará obrigado a remunerá-lo, pelo período correspondente, com o acréscimo de no mínimo $50 \%$ sobre o valor da remuneração da hora normal de trabalho (CLT art. 71, parágrafo $\left.4 .^{\circ}\right)^{(1)}$.

Nas jornadas de doze horas o intervalo para repouso ou alimentação deve ser de uma hora, computada dentro do período de trabalho, uma vez que a jornada diária não pode exceder a esse limite de tempo.

A CLT $^{(1)}$, por meio do artigo 66, estabelece, ainda, que entre duas jornadas de trabalho é obrigatório um intervalo de, pelo menos, onze horas consecutivas para o descanso.

\section{Horas extraordinárias}

O período que excede a jornada normal de trabalho é considerado hora extraordinária, devendo ser remunerada com acréscimo de, no mínimo, $50 \%$ sobre o valor da remuneração da hora normal de trabalho (art. $7^{\circ}$, inciso XVI, da CF/ $88)^{(2)}$. Convém lembrar que as horas extraordinárias ocorrem com maior frequiência nas jornadas de seis e oito horas, sendo que no período das vinte e duas horas de um dia e cinco horas da manhã do dia seguinte deve haver remuneração adicional correspondente a vinte por cento relativo ao adicional noturno, conforme concede a regulamentação específica para esse fim (art. 73 da CLT) ${ }^{(1,5)}$. Desse modo, devemos também lembrar que a convenção coletiva de trabalho da categoria, geralmente amplia o direito dos empregados, negociando índices superiores a 50\% na hora extraordinária e superior a $20 \%$ no adicional noturno ${ }^{(3)}$. Assim, se o funcionário trabalha das dezesseis às vinte e duas horas, mas é convocado para estender seu período de trabalho até meia noite em um determinado dia, ele terá direito ao adicional de vinte por cento sobre essas duas horas noturnas e também terá direito a cinqüenta por cento sobre essas duas horas extraordinárias. Se o funcionário ultrapassa seu horário de trabalho habitual, por exemplo, trabalhando no turno da manhã das sete às treze horas ou da tarde, das treze às dezenove horas, ele terá direito a receber horas extraordinárias correspondentes às horas excedentes trabalhadas, podendo ainda essas horas ser computadas no Banco de Horas, de acordo com o interesse do empregador.

O cálculo da hora extraordinária noturna tem como base a hora reduzida noturna, que por ficção legal corresponde a cinqüenta e dois minutos e trinta segundos, das vinte e duas horas de um dia às cinco horas do dia seguinte. Neste período, a remuneração terá um acréscimo de $20 \%$ sobre a hora normal e sobre a hora noturna incidirá ainda outro adicional de $50 \%$ (no mínimo) $^{(6)}$.

De acordo com o art. 61 da CLT $^{(1)}$, o empregado não está obrigado a prestar o serviço extraordinário se não houver acordo escrito, norma coletiva ou necessidade imperiosa.

Ocorrendo necessidade imperiosa, a duração do trabalho poderá exceder o limite legal ou convencionado, seja 
para fazer face ao motivo de força maior, seja para atender à realização ou conclusão de serviços inadiáveis ou cuja inexecução possa acarretar prejuízo manifesto (art. 61 da CLT $)^{(1)}$.

Na enfermagem essa situação ocorre com muita freqüência, uma vez que imprevistos de diversas naturezas podem impossibilitar a manutenção do quantitativo de pessoal necessário para a consecução das atividades assistenciais, comprometendo, desta forma, a obrigação ético-legal da instituição e do profissional de zelar e assegurar, ao cliente, uma assistência de enfermagem isenta de danos decorrentes de negligência, imperícia ou imprudência (arts. 16 e 24 do Código de Ética dos Profissionais de Enfermagem) ${ }^{(7)}$.

Assim, supondo que o enfermeiro intensivista que trabalha no período da tarde seja informado que seu colega do período seguinte vai se atrasar por duas horas, devido a problemas particulares, e não havendo outro enfermeiro disponível, este profissional encontra-se diante de uma necessidade imperiosa, qual seja a de dar continuidade à assistência até a chegada do colega.

A fim de diminuir os conflitos gerados pelas horas excedentes, a Lei ${ }^{\circ}{ }^{\circ}$ 9.601/98 instituiu o Banco de Horas, onde o excesso de horas trabalhadas num dia não é pago como horas extraordinárias, mas sim compensadas com a diminuição da jornada em outro dia, dentro do período máximo de um ano ${ }^{(8)}$. Essa prática costuma ser adotada com regularidade nos serviços públicos de forma geral e, na área de enfermagem, particularmente, também no setor privado.

Verificamos, ainda, que nos serviços de enfermagem a passagem de plantão incide, freqüentemente, no aumento da jornada diária de trabalho, fazendo com que essa se estenda além das seis, oito ou doze horas previstas.

Uma estratégia administrativa adotada por algumas instituições para sanar esse problema é a sobreposição do horário das jornadas ou a concessão de uma folga compensatória ao trabalhador, correspondente ao tempo diário utilizado para a realização de tal atividade. Exemplo: considerando uma jornada de trabalho de trinta e seis horas semanais, no qual o tempo previsto para passagem de plantão é de quinze minutos ao dia, tem-se, após seis dias, mais noventa minutos trabalhados, que corresponde a trezentos e sessenta minutos/mês. Esse tempo eqüivale a seis horas/mês, fazendo jus à concessão de mais uma folga/mês.

No que se refere aos gerentes ou ocupantes de cargos de confiança, que recebem gratificação de função, o art. 62 , inciso II da CLT ${ }^{(1)}$, determina que somente farão juz às horas extraordinárias aqueles cujas gratificações sejam inferiores ao valor do salário efetivo, acrescido de $40 \%$. Esse inciso também se aplica para a enfermagem.

Diante do exposto julgamos que a solicitação de horas extraordinárias aos profissionais de enfermagem deve ser evitada, principalmente, se considerarmos que o indivíduo convocado para realizar hora suplementar estará cumprindo mais uma jornada de trabalho, o que pode contribuir para a ocorrência de acidentes de trabalho bem como para a incidência de erros técnicos que comprometam a segurança e a integridade dos pacientes.

\section{Descanso semanal Remunerado (DSR)}

De acordo com o artigo $1 .^{\circ}$ da Lei 605/49, todo empregado tem direito ao repouso semanal remunerado, de vinte e quatro horas consecutivas, aos domingos e nos feriados civis e religiosos, de acordo com a tradição local ${ }^{(8)}$.

Os artigos 67 da CLT e $7^{\circ}$ da CF/88 determinam que o DSR se dê, preferencialmente, aos domingos, salvo se a empresa estiver autorizada a agir diferentemente, ou em caso de força maior ${ }^{(5)}$. A Portaria Ministerial (MT 417/66), no entanto, exige que cada empregado usufrua ao menos um domingo/mês ${ }^{(5)}$.

Apesar do empregador poder alterar o dia de descanso do domingo para outro dia, não poderá elaborar escala de repouso semanal que obrigue o empregado a trabalhar além de sete dias seguidos, sem o repouso correspondente, sob pena de pagá-lo em dobro como sanção pela inobservância desse direito ${ }^{(9)}$.

No âmbito da enfermagem a transferência do DSR do domingo para qualquer outro dia da semana é muito comum, dado o caráter ininterrupto da assistência e a necessidade imperiosa de assegurar ao paciente uma continuidade do cuidar. Entretanto, é importante que o trabalhador possa folgar também aos domingos, pois esse é o dia em que os filhos, esposa, amigos, estão juntos por mais tempo, o que favorece o fortalecimento dos laços afetivos e sociais.

Assim, deve-se garantir o direito do trabalhador em usufruir uma folga/ mês no domingo, bem como observar a orientação legal do Tribunal Superior do Trabalho, para que não trabalhe além de sete dias consecutivos, já que o direito ao DSR é preceito de ordem pública e de raiz constitucional ${ }^{(5)}$.

No que diz respeito à concessão do DSR referente aos feriados, os profissionais de enfermagem tem direito a um número de folgas correspondentes ao número de dias de feriados não coincidentes com o domingo. $\mathrm{O}$ número de dias de feriados varia de acordo com o ano, em função da quantidade de feriados estabelecidos por leis federais, estaduais e municipais. Como os feriados estaduais e municipais diferem de Estado para Estado e de cidade para cidade, deverão ser observados o número de feriados previstos pela instituição.

\section{Alterações de turnos de trabalho}

Há autores ${ }^{(6)}$ que consideram lícitas as mudanças ou alterações de horário dentro de um mesmo turno de traba- 
lho, bem como a supressão das horas noturnas e a transferência do período noturno para o diurno. Nesse sentido, a Súmula 265 do TST orienta que a transferência para o período diurno de trabalho implica na perda do direito ao adicional noturno ${ }^{(5)}$.

Corroborando esse entendimento, o Tribunal Regional do Trabalho (TRT/SP) apresentou Recurso Ordinário (RO número 02850200856), acordando que o adicional decorrente de trabalho noturno, mesmo após dois anos, pode ser suprimido sem ônus para o empregador, quando o mesmo transfere o empregado para outro turno de trabalho ${ }^{(5)}$.

A atividade laboral noturna e seu respectivo adicional não se integram a título definitivo ao contrato de trabalho por constituir atividade com maior risco de agravo à saúde e de prejuízo ao convívio familiar e social do empregado ${ }^{(5)}$. No entanto, este autor entende, ainda, que se o trabalhador realizou trabalho noturno durante muito tempo ou se essa condição consta expressamente no seu contrato de trabalho, não é lícito ao empregador transferí-lo para o período diurno. O ideal seria que a empresa acordasse com seus empregados a implantação de rodízios ${ }^{(10)}$.

Na enfermagem, a alteração de turnos de trabalho, freqüentemente, gera conflitos e insegurança para o enfermeiro, que diante da necessidade do serviço ou por problemas de desempenho do funcionário, precisa alterar seu turno de trabalho. Nestas situações entendemos que o enfer- meiro deva buscar anuência escrita do funcionário, explicando-lhe suas razões e estabelecendo acordos favoráveis a ambas as partes.

\section{CONSIDERAÇÕES FINAIS}

Não basta ao enfermeiro conhecer as leis e os direitos trabalhistas, é preciso cumprí-los e fazer com que sejam cumpridos, buscando resguardar os interesses da categoria e da clientela que representa, bem como o comprometimento ético-político das instituições prestadores de serviços de saúde ${ }^{(11)}$.

Dessa forma, as ações gerenciais do enfermeiro devem estar em conformidade com as normatizações ético-legais vigentes. Dado o caráter dinâmico dessas orientações, o enfermeiro deve atualizar continuamente seus conhecimentos, fundamentando o seu agir profissional de forma consciente e responsável, com o intuito de minimizar possíveis implicações legais e fortalecer a legitimidade das relações de trabalho.

A conformação do exercício profissional com o processo legal, ampliam as possibilidades do enfermeiro atuar junto à equipe com mais propriedade e segurança, respeitando os direitos dos profissionais e dos pacientes, reduzindo, ainda, eventuais problemas jurídicos inerentes aos direitos e deveres trabalhistas.

\section{REFERÊNCIAS}

(1) Nelson M, organizador. Consolidação das leis do trabalho, legislação previdenciária. São Paulo: Revista dos Tribunais; 2001.

(2) Brasil. Constituição Federativa do Brasil. 25a ed. São Paulo: Saraiva; 2000.

(3) Ribeiro ET. Curso de rotinas práticas de direito e de processo do trabalho. $3^{\mathrm{a}}$ ed. Porto Alegre: Síntese; 2002.

(4) Martins SP. Direito processual do trabalho: doutrina e prática forense. São Paulo: Atlas; 1999.

(5) Carrion V. Comentários à consolidação das leis do trabalho: legislação complementar jurisprudência. $25^{\mathrm{a}}$ ed. São Paulo: Saraiva; 2000 .

(6) Führer MCA, Führer MRE. Resumo de direito administrativo. $8^{a}$ ed. São Paulo: Malheiros; 2000.
(7) Conselho Regional de Enfermagem de São Paulo. Resolução n. 240, de 30 de agosto de 2000. In: Conselho Regional de Enfermagem de São Paulo. Documentos básicos de enfermagem: enfermeiros, técnicos e auxiliares. São Paulo: COREN-SP; 2001.

(8) Assan OE. Carteira forense. São Paulo: Julex; 2000.

(9) Manus PPT. Direito do trabalho. $4^{\mathrm{a}}$ ed. São Paulo: Atlas; 2000.

(10) Saad EG, Saad JED, Branco AMSC. Consolidação das leis do trabalho comentada. $3^{\text {a }}$ ed. São Paulo: LTr; 2004.

(11) Freitas GF. Responsabilidade ético-legal do enfermeiro. In: Oguisso T, organizadora. Trajetória histórica e legal da enfermagem. São Paulo. Manole; 2005. (Série Enfermagem). 